\title{
Lower Ionospheric turbulence variations during the intense tectonic activity in Eastern Aegean area
}

\author{
Emmanuel M. Scordilis*,1, Micheal E. Contadakis ${ }^{2}$, Filippos Vallianatos ${ }^{3}$, \\ Spiridon Spatalas ${ }^{2}$ \\ (1) Department of Geophysics, Aristotle University of Thessaloniki, Greece \\ (2) Department of Geodesy and Surveying, Aristotle University of Thessaloniki, Greece \\ (3) Department of Geophysics and Geothermy, National \& Kapodistrian University of Athens, Greece
}

Article history: received June 20, 2018; accepted May 7, 2019

\begin{abstract}
This paper may be considered as an additional approval of the way the tectonic activity affects the lower Ionosphere. The results of our investigation, on the occasion of the recent East Aegean tectonic activity, indicate that the High - Frequency limit, $\mathrm{f}_{\mathrm{o}}$, of the ionospheric turbulence content, increases as the site and the time of the earthquake occurrence is approaching, pointing to the earthquake location.We conclude that the Lithosphere Atmosphere Ionosphere Coupling (LAIC) mechanism through acoustic or gravity wave could explain this phenomenology, as a result of a the frequency differential damping of the propagating turbulent in the ionosphere. Proper use of this result may lead to a method of earthquake hazard mitigation using the byproducts of the Global Positioning Network (actually Total Electron Contain, TEC, estimations) which are available freely.
\end{abstract}

Keywords: Seismicity, Lower Ionosphere, Ionospheric turbulence, Brownian walk, Aegean area.

\section{Introduction}

It is argued that tectonic activity during the earthquake preparation period produces anomalies at the ground level which propagate upwards in the troposphere as Acoustic or Standing gravity waves [Hayakawa et al., 2011; Hayakawa, 2011; Hayakawa et.al., 2018]. These Acoustic or Gravity waves affect the turbulence of the lower ionosphere, where sporadic Es-layers may appear too, as well as the turbulunce of the F layer [Liperovsky et al., 2005]. Subsequently the produced disturbance starts to propagate in the ionosphere's waveguide as gravity wave. The inherent frequencies of the acoustic or gravity wave, range between $0.003 \mathrm{~Hz}$ (period $5 \mathrm{~min}$ ) and $0.0002 \mathrm{~Hz}$ (period 83min), which, according to Molchanov et al. [2004, 2005], correspond to the frequencies of the turbulent produced by tectonic activity during the earthquake preparation period. During this propagation the higher frequencies are progressively damped. Thus, observing the frequency content of the ionospheric turbulence we will observe a decrease of the higher limit of the turbulence frequency band. Our investigations so far, on the occasion of strong earthquakes approve this view. Nevertheless, since the approval of the 


\section{Emmanuel M. Scordilis et al.}

theoretical view depents mainly on the compliance of the observational results to the theoretical clues, further obsrvational results are always welcome.

However, it has to be noted that the original cause of the earth surface perturbation is the increasing stress and the rapture of the rocks at the earthquake preparation area where radon release takes place. The coupling of radon with atmosphere at the earth's surface results to the increase the ionization, temperature [Tramutoli et al., 2018], electromagnetic field and to disturbances in the air electrical contuctivity. These perturbations are transmitted to the Ionosphere by some LAIC Mechanism. The proposed possible hypothesis on the mechanism of coupling between lithospheric activity and ionosphere, is transmission through: a) chemical channels [Pulinets et al., 2018]; b) atmospheric oscillation (or acoustic) channels [Hayakawa et al., 2018] and c) electromagnetic channels [Pulinets et al., 2018, Hayakawa et al., 2018]. Finally, a hypothesis of electrostatic channel has been proposed by Freund [2009] on the basis of positive hole charge carriers release in crustal rocks, that are subjected to ever increasing levels of stress alongside electrons. When the positive holes arrive at the Earth's surface, they can cause massive ionization of the air molecules and positive surface potential. Subsequently these perturbations are transmitted to the Ionosphere.

In this paper we investigate the ionospheric turbulence from TEC observations before and during the intense seismic activity of May to August 2017 in Eastern Aegean $\left(26.5^{\circ} \leq \lambda \leq 27.5^{\circ} \mathrm{E}, 36.5^{\circ} \leq \varphi \leq 39.0^{\circ} \mathrm{N}\right)$. In order to select the proper TEC estimations provider we have in mind that: GLONASS and GPS systems provide TEC values through Global Ionospheric Maps each 15 minutes, that is potential observation of TEC variations with frequencies $<555.5 \mu \mathrm{Hz}$ [see for instance Jann-Yenq (Tiger) Liu et al., 2018]. Another option would be to process the data of the desired stations with a proper software in order to gain higher frequency resolution of the TEC variation over a certain area. For instance, Watson et al. [2016] investigated the Magnetosphere-Ionosphere coupling through the TEC variations over the North pole using data from proper GPS stations in the frequency band $<100 \mathrm{mHz}$. The IONOLAB program provides TEC values in the frequency region $<3.33 \mathrm{mHz}$ [Arikan et al., 2009] for selected stations of EUREF and GLONASS networks. We use TEC estimations of IONOLAB because they are the most suitable for our program.

The Total Electron Content (TEC) data of 5 Global Positioning System (GPS) stations of the EUREF network, provided by IONOLAB (Turkey), were analysed using Discrete Fourier Analysis to investigate the TEC variations [Contadakis et al., 2008; Contadakis et al., 2012; Contadakis et al., 2015].

\section{Seismotectonic Information}

Aegean is considered among the most seismically active regions of the Alpine-Himalayan Mountain Belt. The Aegean itself is a microplate, which is bounded: a) by the western extension of the right-lateral North Anatolian Fault Zone to the north and b) by the Hellenic Arc to the south, along which the Mediterranean plate is subducting under the Aegean [e.g., Ketin, 1948; Papazachos and Comninakis, 1970, 1971; McKenzie, 1972, 1978; Dewey and Şengör, 1979; Le Pichon and Angelier, 1979, 1981; Şengör et al., 1985]. The eastern boundary of the Aegean plate is characterized by N-S extension expressed along normal faults striking almost E-W [e.g. Papazachos et al., 1998]. This region covers western Turkey and is oriented by the Northern Anatolian Fault to the north, extending southwards down to the $30^{\circ} \mathrm{E}$ meridian.

Two strong earthquakes occurred during summer of 2017 in east Aegean, close to the western coasts of Turkey. The first occurred on June 12, 2017 (12:28 GMT), with magnitude Mw=6.3, close to the south coasts of Lesvos Island while the second was stronger with Mw=6.6 and occurred on July 20, 2017 (22:31 GMT) with its epicenter located offshore northeastern Kos Island close to Gokova Bay (Figure 1). Table 1 lists information on the focal parameters of strong shallow earthquakes that occurred in these regions and their vicinities since 1900 .

An almost pure normal fault striking WNW-ESE and dipping to the SSW (GCMT solution: strike $=110^{0}$, $\operatorname{dip}=47^{0}$, rake $=-87^{0}$ ) was responsible for the generation of the first of them. The length of the ruptured area was $20 \mathrm{~km}$, its width $10 \mathrm{~km}$, the average slip of the asperity $\sim 50 \mathrm{~cm}$ and the peak slip $\sim 1 \mathrm{~m}$ while the rupture was unilateral propagating towards WNW at a relatively high speed of $\sim 3.1 \mathrm{~km} / \mathrm{s}$ [Kiratzi, 2018].

The second earthquake was generated at the NW edge of the Quaternary Gökova Bay graben [e.g. Saltogianni et al., 2017; Tiryakioğlu et al., 2018], also on an almost pure normal fault, striking E-W and dipping to the south (GCMT 


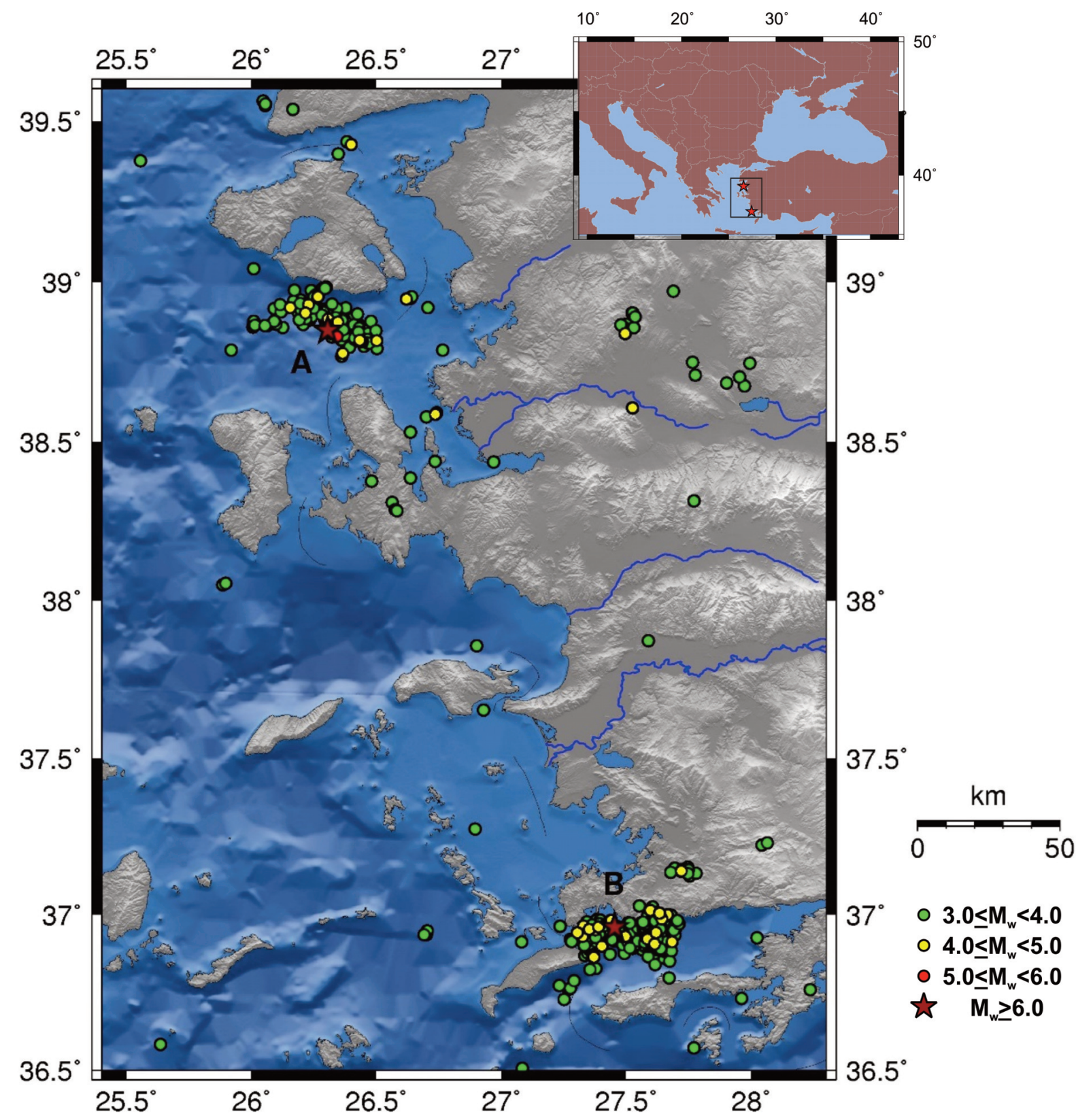

Figure 1. Seismic activity in E. Aegean during the second half of 2017. Red stars denote the epicenters of the two mainshocks, (A): 12/6/2017 and (B): 20/7/2017.

(Data from: http://geophysics.geo.auth.gr/the_seisnet/WEBSITE_2005/station_index_en.html http://bbnet.gein.noa.gr/HL/seismicity/catalogues/manual-alerts)

solution: strike $=88^{0}$, dip $=55^{0}$, rake $=-96^{\circ}$ ). This fault is located ENE of Kos Island at the northern margin of the Gökova Gulf and is controlled by the Gökova Fault Zone which is one of the most active structures in SW Anatolia [Tiryakioğlu et al., 2018]. The earthquake produced a minor tsunami with a maximum run-up of about $\sim 2 \mathrm{~m}$ [Yalciner et al., 2017]. The seismic fault had a length of $\sim 25 \mathrm{~km}$ and ruptured the upper crust from the surface (sea bed) to the depth of $12 \mathrm{~km}$ [Saltogianni et al., 2017]. 
Emmanuel M. Scordilis et al.

\begin{tabular}{cccccc}
\multicolumn{7}{c}{ REGION (A) } & & & \\
Year & Date & Origin Time $(\mathrm{GMT})$ & Lat $\left({ }^{\circ} \mathrm{N}\right)$ & Lon $\left({ }^{\circ} \mathrm{E}\right)$ & $\mathrm{M}_{\mathrm{W}}$ \\
\hline 1933 & April 23 & $05: 57: 37$ & 36.80 & 27.30 & 6.6 \\
\hline 1941 & May 23 & $19: 51: 52$ & 37.00 & 28.10 & 6.0 \\
\hline 1941 & December 13 & $06: 15: 59$ & 37.00 & 28.20 & 6.2 \\
\hline 1968 & December 05 & $07: 52: 11$ & 36.60 & 27.10 & 6.0 \\
\hline Year & Date & REGION (B) & & & MW \\
\hline 1919 & November 18 & $21: 54: 50$ & 39.10 & 27.40 & 7.0 \\
\hline 1939 & September 22 & $00: 36: 32$ & 39.00 & 27.00 & 6.6 \\
\hline 1944 & October 06 & $02: 34: 41$ & 39.50 & 26.60 & 6.9 \\
\hline 1949 & July 23 & $15: 03: 30$ & 38.68 & 26.13 & 6.7 \\
\hline 1981 & December 19 & $14: 10: 51$ & 39.00 & 25.26 & 7.2 \\
\hline
\end{tabular}

Table 1. Strong shallow earthquakes that occurred since 1900 in the vicinity of the two strong mainshocks (REGION A: 12/6/2017, M=6.3, SSE of Lesvos Isl. and REGION B: 21/7/2017, M=6.6, ENE of Kos Isl.). (Information from Papazachos and Papazachou, 2003).

Table 2 displays the focal parameters of the strong $\left(\mathrm{Mw}_{\mathrm{w}} \geq 5.0\right)$ earthquakes which occured in the area of the two major earthquakes from $01 / 05 / 2017$ to $30 / 8 / 2017$.

\begin{tabular}{|c|c|c|c|c|c|c|c|c|}
\hline & Year & Date & $\begin{array}{l}\text { Origin Time } \\
\text { (GMT) }\end{array}$ & Region & Lat $\left({ }^{\circ} \mathbf{N}\right)$ & Lon $\left({ }^{\circ} \mathbf{E}\right)$ & $\begin{array}{c}\text { Depth } \\
(\mathbf{k m})\end{array}$ & $\mathbf{M}_{\mathrm{w}}$ \\
\hline 1 & 2017 & May 17 & $11: 30: 32$ & $51 \mathrm{~km}$ NE of Karpathos & 36.03 & 27.49 & 22 & 5.1 \\
\hline 2 & 2017 & May 27 & $15: 53: 23$ & $134 \mathrm{~km}$ NNE of Samos & 38.76 & 27.83 & 24 & 5.2 \\
\hline 3 & 2017 & June 12 & $12: 28: 38$ & $38 \mathrm{~km}$ SSE of Lesvos & 38.84 & 26.36 & 12 & 6.3 \\
\hline 4 & 2017 & June 17 & $19: 50: 05$ & $39 \mathrm{~km}$ SSE of Lesvos & 38.85 & 26.43 & 12 & 5.3 \\
\hline 5 & 2017 & July 15 & $20: 30: 15$ & $64 \mathrm{~km}$ SSE of Iraklion & 34.82 & 25.46 & 5 & 5.3 \\
\hline 6 & 2017 & July 20 & $22: 31: 11$ & $15 \mathrm{~km}$ ENE of Kos & 36.96 & 27.43 & 10 & 6.6 \\
\hline 7 & 2017 & July 31 & $21: 29: 09$ & 146 km SSW of Rethimnon & 34.14 & 23.91 & 8 & 5.3 \\
\hline 8 & 2017 & August 08 & $07: 42: 21$ & $32 \mathrm{~km}$ ENE of Kos & 37.03 & 27.61 & 5 & 5.1 \\
\hline
\end{tabular}

Table 2. Strong earthquakes that occurred during May-August 2017 in the vicinity of the two strong mainshocks.

\section{TEC Variation Over Mid Latitude Europe}

In the following we investigate the variations of TEC over the broader area of Mediterranean before and during the seismic activity of May to August 2017 in Eastern Aegean $\left(26.5^{\circ} \leq \lambda \leq 27.5^{\circ} \mathrm{E}, 36.5^{\circ} \leq \varphi \leq 39.0^{\circ} \mathrm{N}\right)$. To this purpose we use the TEC estimates provided by IONOLAB (http://www.ionolab.org) [Arikan et al., 2009] for 5 mid 


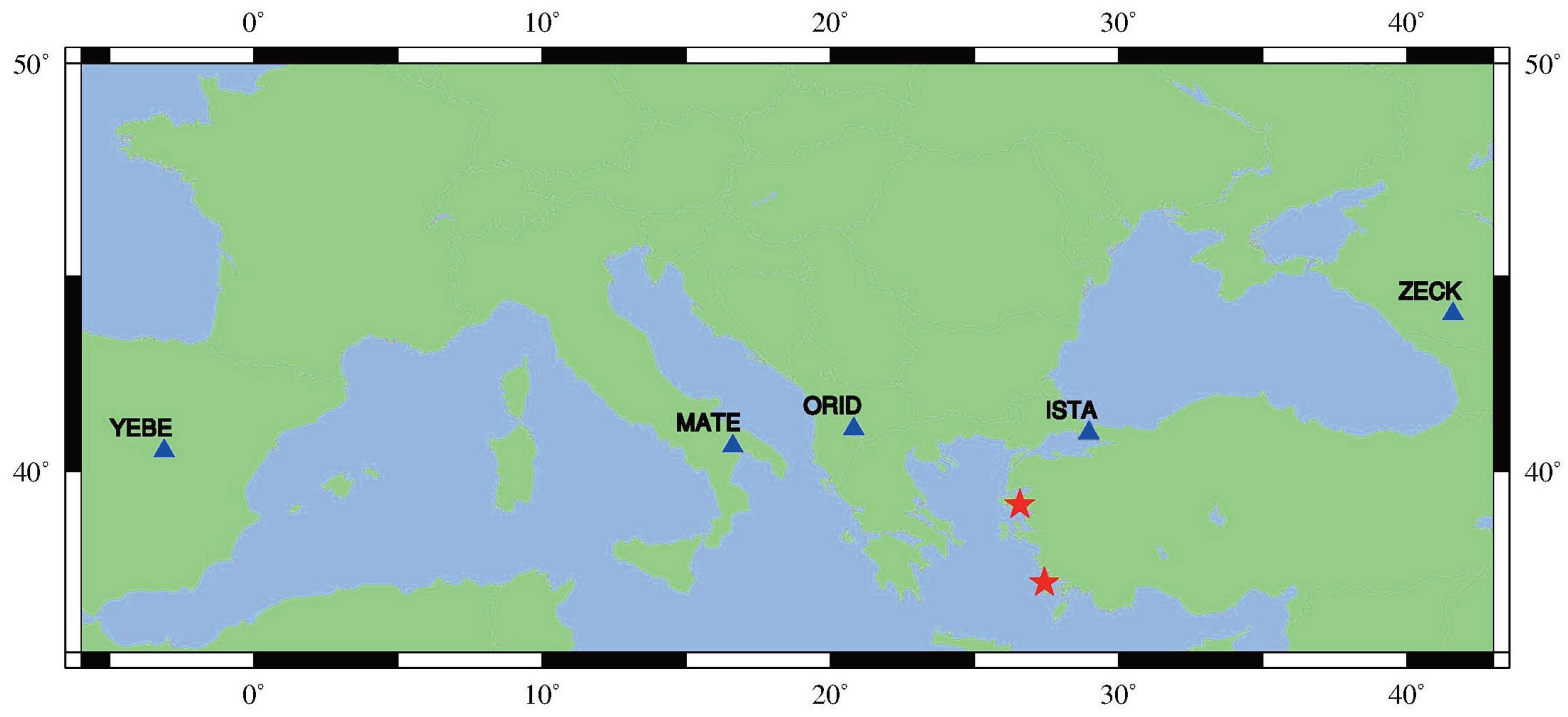

Figure 2. The locus of the five GPS stations (blue triangles) and the epicentres of the two main shocks (red stars).

\begin{tabular}{ccccc} 
GPS Site & Lat $\left({ }^{\circ} \mathbf{N}\right)$ & Lon $\left({ }^{\circ} \mathbf{E}\right)$ & $\begin{array}{c}\text { Distance from } \\
\text { Lesvos }(\mathbf{k m})\end{array}$ & $\begin{array}{c}\text { Distance from } \\
\text { Kos (km) }\end{array}$ \\
\hline Yebes (YEBE) & 40.520000 & -3.088600 & 2530 & 2649 \\
\hline Matera (MATE) & 40.667267 & 16.604712 & 867 & 1010 \\
\hline Ohrid (ORID) & 41.123657 & 20.801771 & 539 & 730 \\
\hline Istanbul (ISTA) & 41.010000 & 28.960278 & 298 & 498 \\
\hline Zelenchukskaya (ZECK) & 43.857071 & 41.585293 & 1358 & 1453
\end{tabular}

Table 3. Distance of GPS stations from the epicenter of the two mainshocks.

latitude GPS stations of EUREF which cover epicentral distances from the active areas ranging from $298 \mathrm{~km}$ to 2649 $\mathrm{km}$, for the time periods between $01 / 05 / 2017$ to $25 / 08 / 2017$. The selected GPS stations are located at about the same latitude and, therefore, it is expected to be equally affected from the Equatorial Anomaly as well as from the Auroral storms. Table 3 displays the 5 EUREF stations while Figure 2 displays the sites of the five GPS stations and the epicentres of the two mainshocks.

The IONOLAB TEC estimation system uses a single station receiver bias estimation algorithm, IONOLABBIAS, to obtain daily and monthly averages of receiver bias and is successfully applied to both quiet and disturbed days of the ionosphere for station position at any latitude. In addition, TEC estimations with high resolution are also possible [Arikan et al., 2009].

IONOLAB system provides (in its web-site http://www.ionolab.org/) comparison graphs of its TEC estimations with respective estimations of the other TEC providers of IGS. In this work only TEC estimations in perfect accordance among all providers were used. The TEC values are given in the form of a Time Series with a sampling gap (resolution) of 2.5 minutes. Figures 3 and 4 display the TEC variation over the 5 EUREF stations for the time periods 17/05/2017-25/06/2017 and 01/07/ 2017-01/08/2017, respectively. 
Emmanuel M. Scordilis et al.
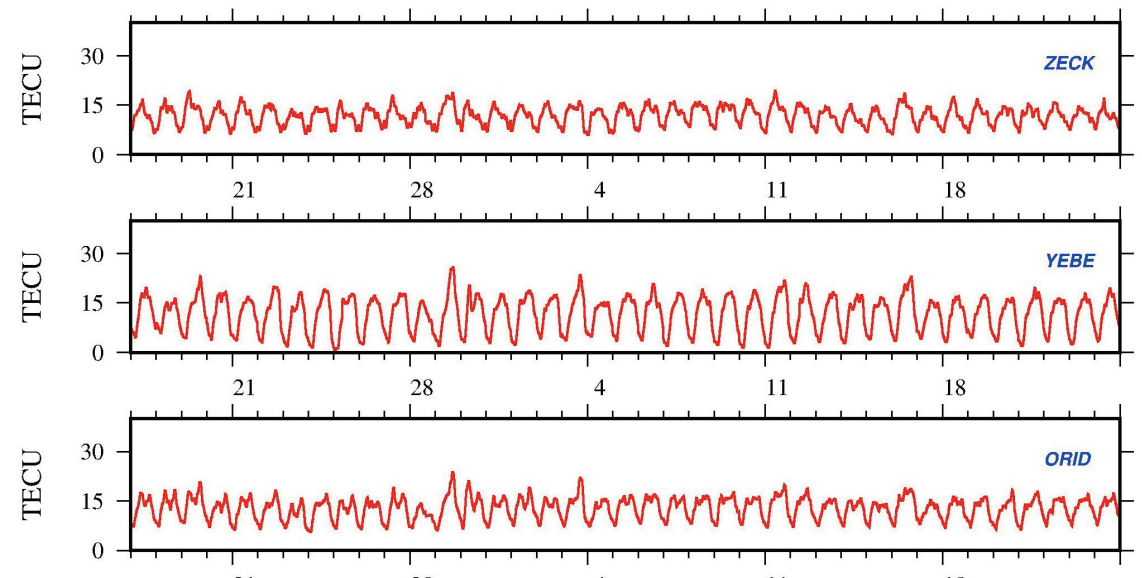

$21-28 \quad 4 \quad 11 \quad 18$
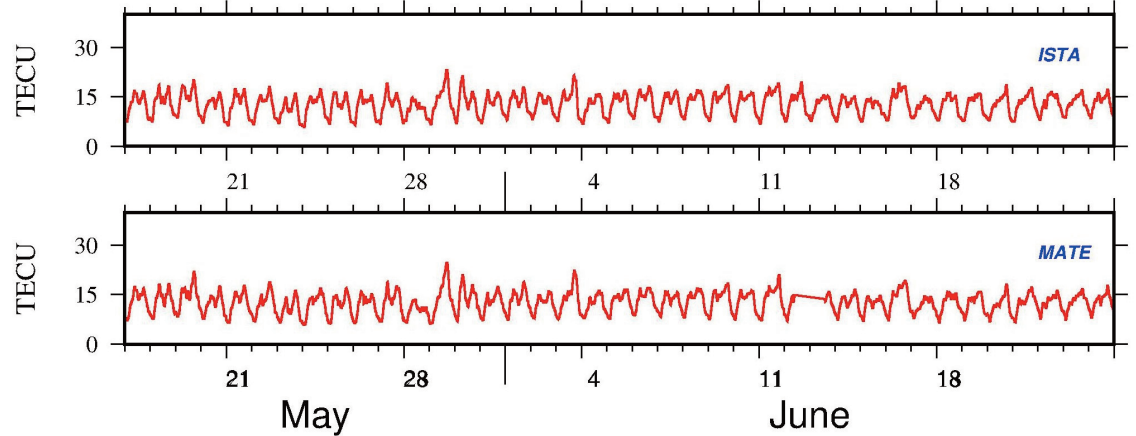

Figure 3. The TEC variation over the 5 EUREF stations for the period 17/05/2017-25/06/2017 (around the Lesvos event).
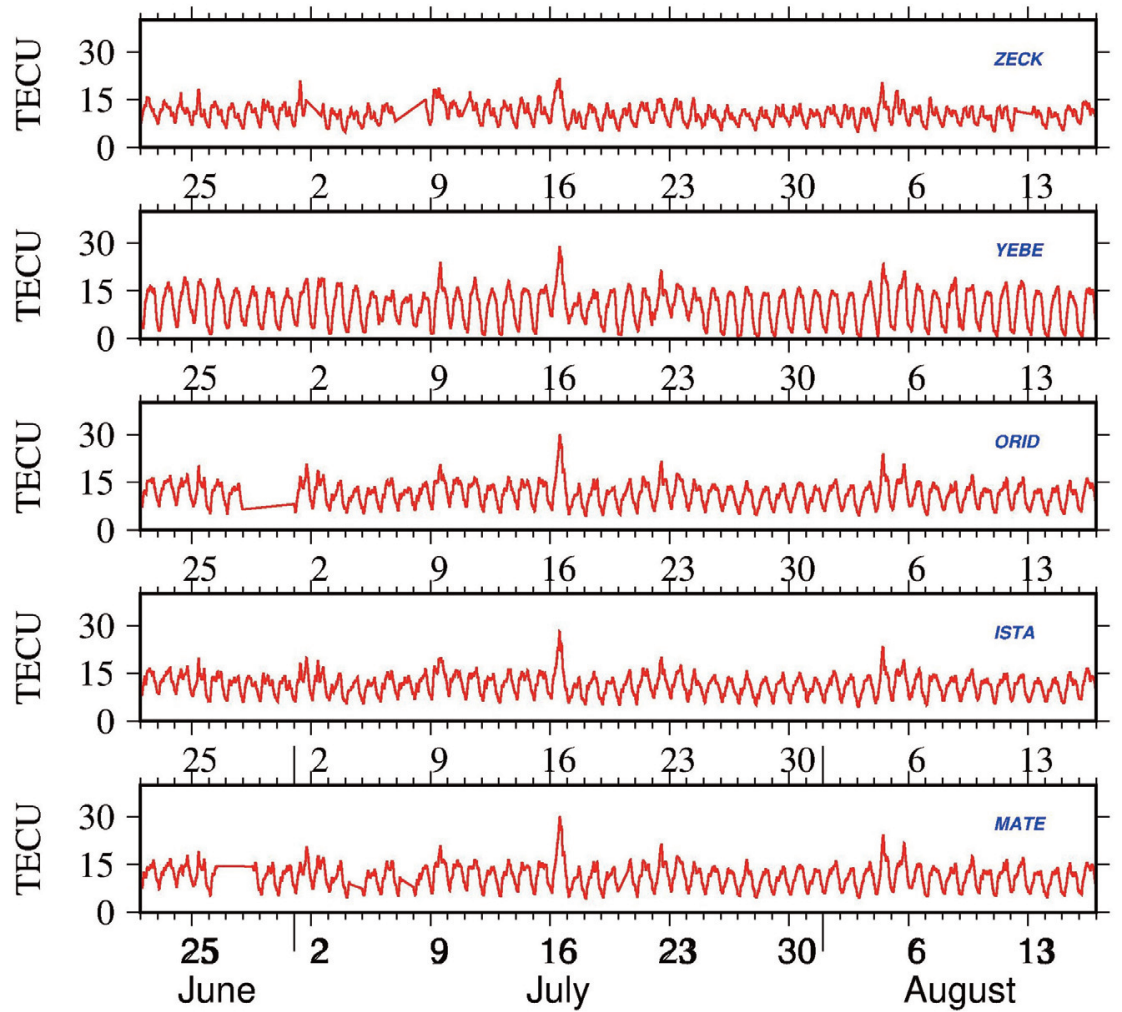

Figure 4. The TEC variation over the 5 EUREF stations for the period 01/07/2017-01/08/2017 (around the Kos event). 


\section{Fast Fourier Transform Analysis}

It is well known that TEC variations reveal ionospheric variations of different nature: a) global, like earth revolution, earth rotation, earth-tides, variations of the geomagnetic field, solar activity etc. [Svets et al., 2004; Biagi et al., 2003]; b) local, such as atmospheric or underground explosions, volcanoes, extreme weather phenomena [see for instance Afraimovich et al., 2000]; c) earthquakes [Afraimovich et al., 2001; Molchanov et al., 2004; Molchanov et al., 2005; Liperofsky et al., 2005; Shvets et al., 2004]. The turbulence frequency band results from the disturbances of all the above factors. The lower frequencies correspond to the tidal disturbances while the disturbances induced by the tectonic activity belong to the higher frequencies of the turbulence band [Molchanov et al., 2004; Molchanov et al., 2005; Hobie et al., 2007]. Thus, we concentrate our interest to the upper limit of the turbulence frequency band for which the fractal characteristics of the noise allow its determination.

The Power Spectrum of TEC variations will provide information on the frequency content of them. Apart of the well known and well expressed tidal variations, for which the reliability of their identification can be easily inferred by statistical tests, small amplitude space-temporal transient variations cannot have any reliable identification by means of a statistical test. Nevertheless looking at the logarithmic power spectrum, we can recognize from the slope of the diagram whether the contributed variations to the spectrum are random or periodical. If they are random the slope will be 0 , which corresponds to the white noise, or -2 which corresponds to the Brownian walk noise, otherwise the slope will be different, the so called Fractal Brownian walk [Turcotte, 1997]. This means that we can trace the presence of periodical variations in the logarithmic power spectrum of TEC variations. As an example, Figure 5 displays the logarithmic power spectrum of TEC variations over the GPS station of Istanbul from 17 to $19 / 06 / 2017$. It is seen that the slope of the diagram up to the $\log (f)=-2.6$, which corresponds to the frequency of $495.16 \mu \mathrm{Hz}$, is -2 . This means that for higher frequencies the TEC variation corresponds to random noise. On the contrary, the TEC variation for lower frequencies can be considered as not random, i.e. turbulent. So we conclude that the upper limit of the turbulent band is $\mathrm{f}_{\mathrm{o}}=495.16 \mu \mathrm{Hz}$. or, equivalently, the lower limit of periods of the contained turbulent is $\mathrm{P}_{\mathrm{O}}=33.6508$ minutes.

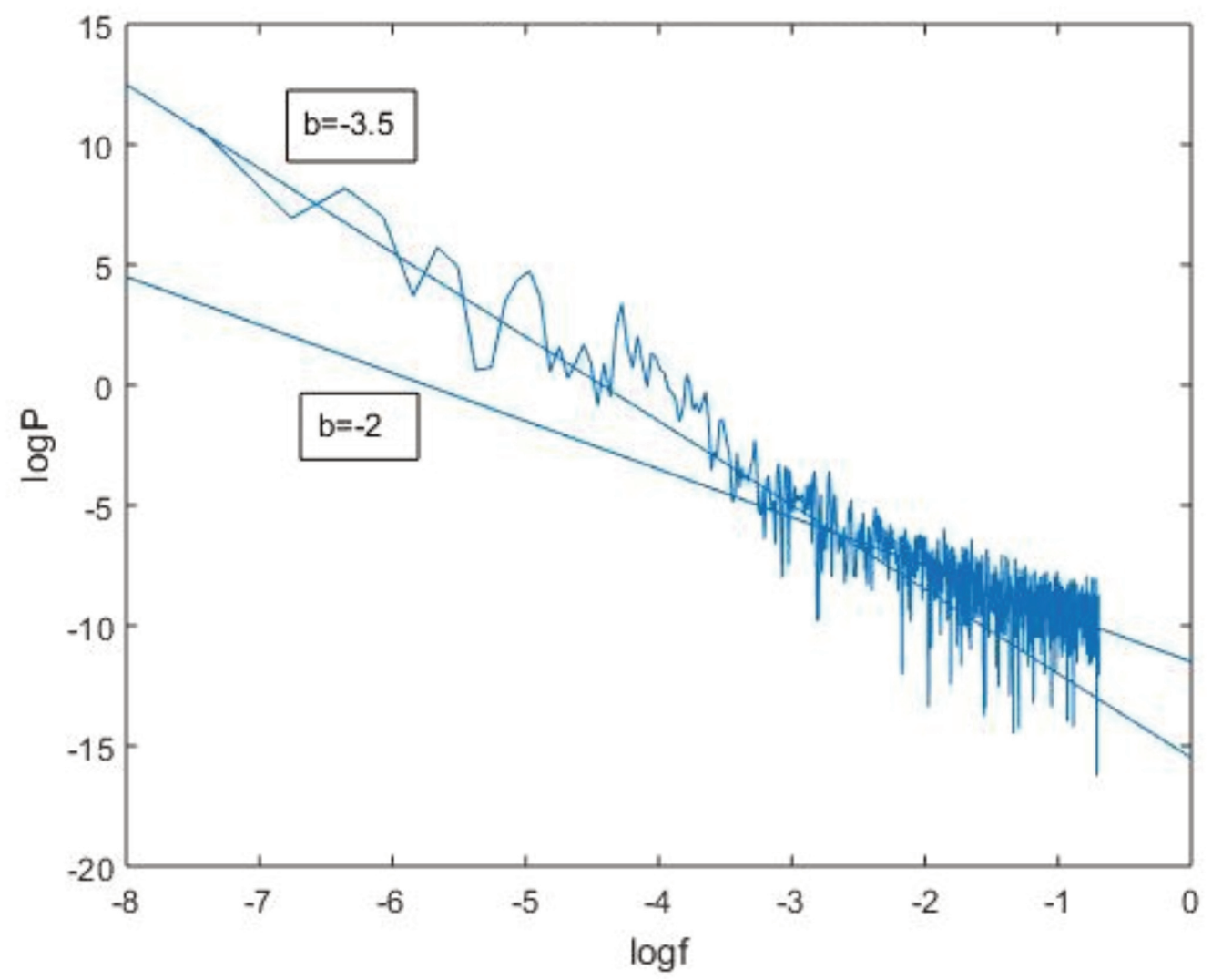

Figure 5. The logarithmic power spectrum of TEC variations over the GPS station of Istanbul around the days of 1719/06/2017. 


\section{Emmanuel M. Scordilis et al.}

\section{Results and discussion}

Figures 6 and 7 display the variation with distance of TEC turbulence frequency band upper limit $\mathrm{f}_{\mathrm{o}}$ and of lower Period limit $\mathrm{P}_{0}$, respectively, over the selected EUREF GPS stations for the days of the shocks, i.e 12 of June (Lesvos mainshock) and 20 of July (Kos mainshock) and for a seismically “quiet” day, the 26 of July. It is shown that at the days of strong earthquakes a strong dependence of the upper frequency $\mathrm{f}_{\mathrm{o}}$ (lower period $\mathrm{P}_{\mathrm{o}}$ ) limit of the Ionospheric turbulent content with the epicentral distance is observed. In particular, the closer of the GPS station to the active area the higher frequency $\mathrm{f}_{\mathrm{o}}$ (lower period $\mathrm{P}_{\mathrm{o}}$ ) limit is. This dependence is not shown at the "quiet day". As it is seen from Figures 6 and 7, the upper frequency limit, $\mathrm{f}_{\mathrm{o}}$, and lower period limit, $\mathrm{P}_{\mathrm{o}}$, of the turbulence band in quiet days, or at remote GPS stations during the days of seismic activity, range between $400-200 \mu \mathrm{Hz}$ or equivalently $41.5-83 \mathrm{~min}$. A brief statistic of our data for the quiet days give mean values: Mean $\left(\mathrm{f}_{\mathrm{o}}\right)=372.7 \pm 75 \mu \mathrm{Hz}$ and $\operatorname{Mean}\left(\mathrm{P}_{\mathrm{o}}\right)=44.71$ $\pm 8.25 \mathrm{~min}$. These period are in the range of the observed Acoustic Gravity Waves on the occasions of strong earthquakes, which are: periods of 30 to $100 \mathrm{~min}$ [Molchanov et al., 2004; Molchanov et al., 2005] or 20 to $80 \mathrm{~min}$ [Horie et al., 2007].

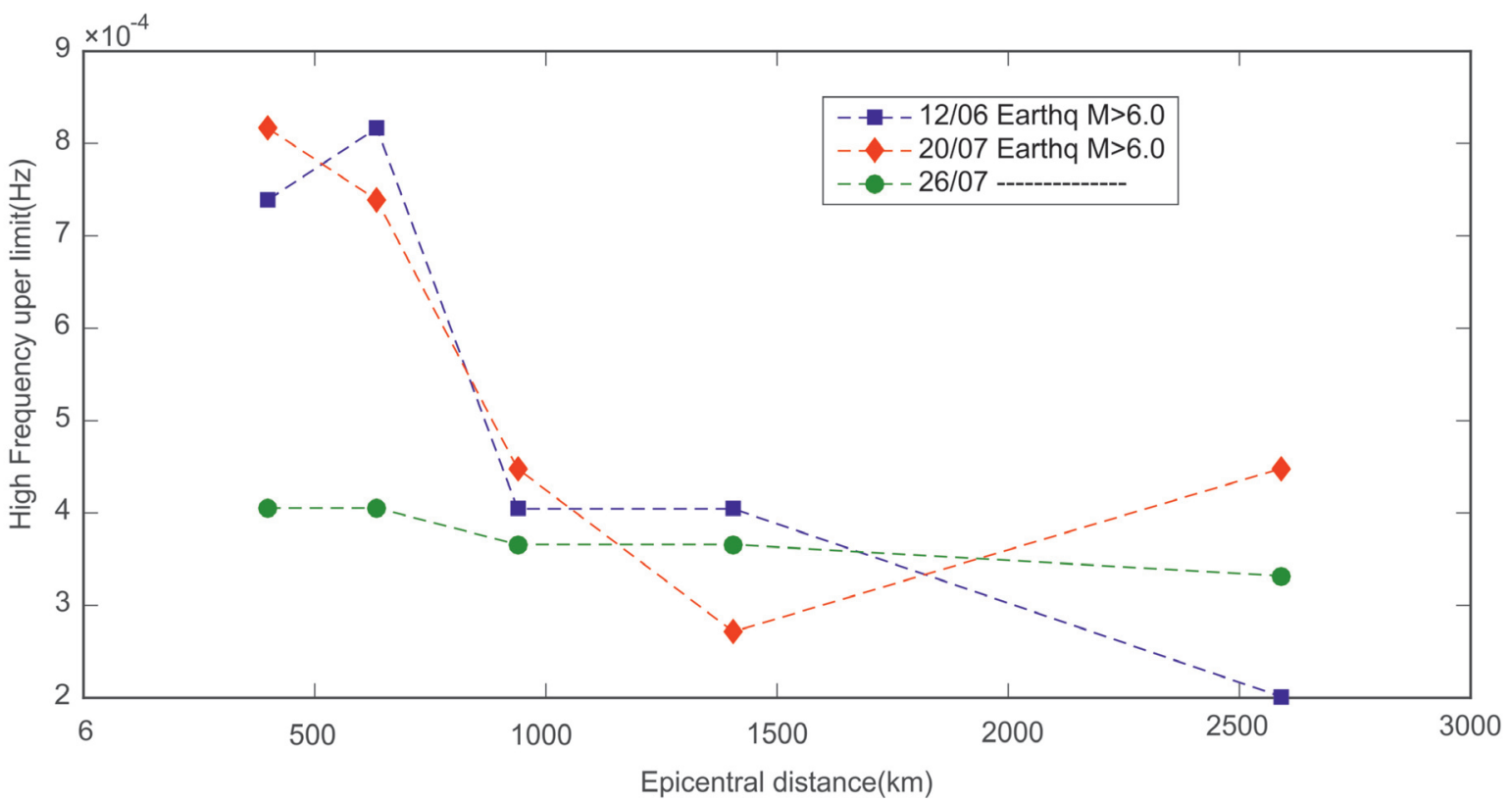

Figure 6. Variation of TEC turbulence frequency limit $\mathrm{f}_{\mathrm{o}}$ over the nearest GPS Stations to the broader area, (ORID and ISTA) of EUREF network, with the epicentral distance around the days of the earthquakes of June 12 (Lesvos main shock) and August 20 (Kos main shock), 2017. The green line corresponts to turbulent frequency limit $\mathrm{f}_{\mathrm{o}}$ in an aseismic day.

Figures 8 and 9 show the variation of the upper frequency $\mathrm{f}_{\mathrm{o}}$ and of the lower period $\mathrm{P}_{\mathrm{o}}$, limits of ionosferic turbulence content over the nearest to the active area GPS stations. In the same figures the occurrence times of strong earthquakes are shown with arrows (red for shocks with $\mathrm{M}_{\mathrm{W}}>6.0$ and black for shocks with 5.0 $<\mathrm{M}_{\mathrm{W}}<6.0$ ). It is seen that at the days of strong earthquakes the ionospheric turbulence upper frequency limit, $\mathrm{f}_{\mathrm{o}}$, increases (or the lower period limit, $\mathrm{P}_{\mathrm{o}}$, decreases). These results indicate time and space convergence of increasing turbulence frequency band upper limit $\mathrm{f}_{\mathrm{o}}$ to the earthquakes occurrence. Hobara et al. [2005] in a study on the ionospheric turbulence in low latitudes concluded that the attribution of the turbulence to earthquake process and not to other sources, i.e. solar activity, storms etc is not conclusive. Nevertheless in our case, the steady monotonic time and space convergence of the frequency band upper limit $\mathrm{f}_{\mathrm{o}}$ increment, to the occurrence of the East Aegean strong earthquakes is a strong indication that the observed turbulence is generated by the respective earthquakes preparation processes. 


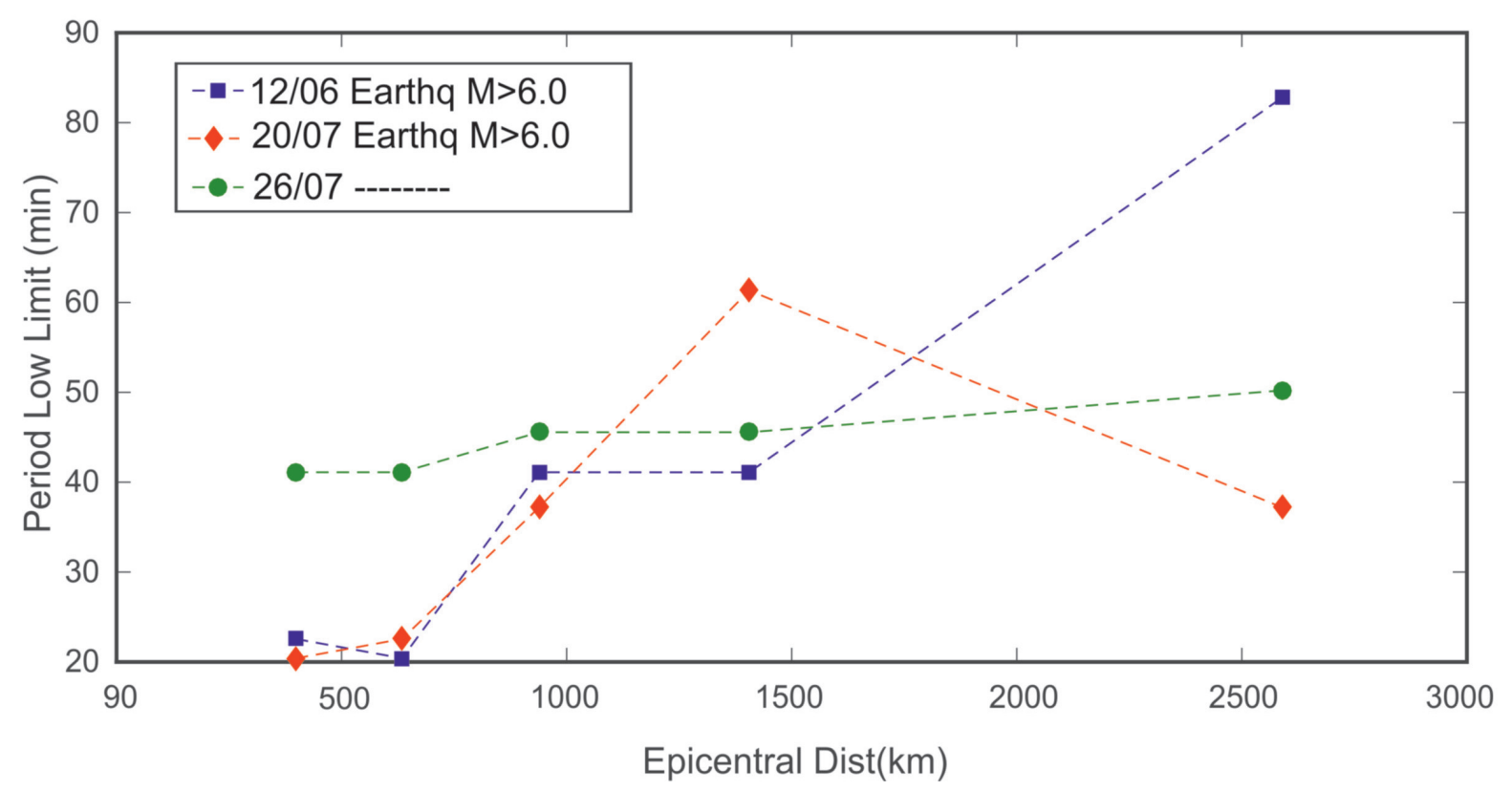

Figure 7. Variation of TEC turbulence period limit $\mathrm{P}_{\mathrm{o}}$ over the nearest GPS Stations to the broader aerea, (ORID and ISTA) of EUREF network, with the epicentral distance around the days of the earthquakes of June 12 (Lesvos main shock) and August 20 (Kos main shock), 2017. The green line corresponts to turbulent period limit $\mathrm{P}_{\mathrm{O}}$ in an aseismic day.

The qualitative explanation of this phenomenology can be offered on the basis of the LAIC: Tectonic activity during the earthquake preparation period produces anomalies at the ground level which propagate upwards in the troposphere as Acoustic or Standing gravity waves [Hayakawa et al. 2011; Hayakawa, 2011]. These Acoustic or Gravity Waves affect the turbulence of the lower ionosphere, where sporadic Es-layers may appear too [Liperovsky et al., 2005], and the turbulence of the F layer. Subsequently, the produced disturbance starts to propagate in the ionosphere's waveguide as gravity wave and the inherent frequencies of the acoustic or gravity waves can be traced on TEC variations [i.e. the frequencies between $0.003 \mathrm{~Hz}$ (period $5 \mathrm{~min}$ ) and $0.0002 \mathrm{~Hz}$ (period 100min)], which, according to Molchanov et al. [2004, 2005] and Horie et al. [2007], correspond to the frequencies of the turbulent induced by the LAIC coupling process to the ionosphere. As we move far from the disturbed point, in time or in space, the higher frequencies (shorter wavelength) variations are progressively attenuated.

It has to be noted that the original cause of the earth surface perturbation is the increasing stress and the rapture of the rocks at the earthquake preparation area where radon release takes place. The coupling of radon with atmosphere at the earth's surface results to the increase the ionization, temperature [Tramutoli et al., 2018], electromagnetic field and to disturbances in the air electrical contuctivity. This perturbation is transmitted to the Ionosphere by some LAIC Mechanism. The proposed possible hypothesis on the mechanism of coupling between lithospheric activity and ionosphere is transmission through (a) chemical channels (Pulinets et al. 2018), (b) atmospheric oscillation (or acoustic) channels [Hayakawa et al., 2018] and (c) electromagnetic channels [Pulinets et al., 2018; Hayakawa et al., 2018]. Finally, a hypothesis of electrostatic channel has been proposed by Freund [2009] on the basis of positive hole charge carriers release in crustal rocks, alongside electrons. When the positive holes arrive at the Earth's surface, they can cause massive ionization of the air molecules and positive surface potential. Subsequently these perturbations are transmitted to Ionosphere. From this approach for the LAIC mechanism, we believe that the hypothesis of the atmospheric oscillation (or acoustic) channel [Hayakawa et al., 2018] is most suitable for the explanation of our observations, since the observed frequency band of the suggested gravity waves of this work comply with the observed frequency bands of the Internal Atmospheric Gravity waves (Acoustic standing waves) by Horie et al. [2007] and Molchanov et al. [2004, 2005], as it is already mentioned. 


\section{Emmanuel M. Scordilis et al.}

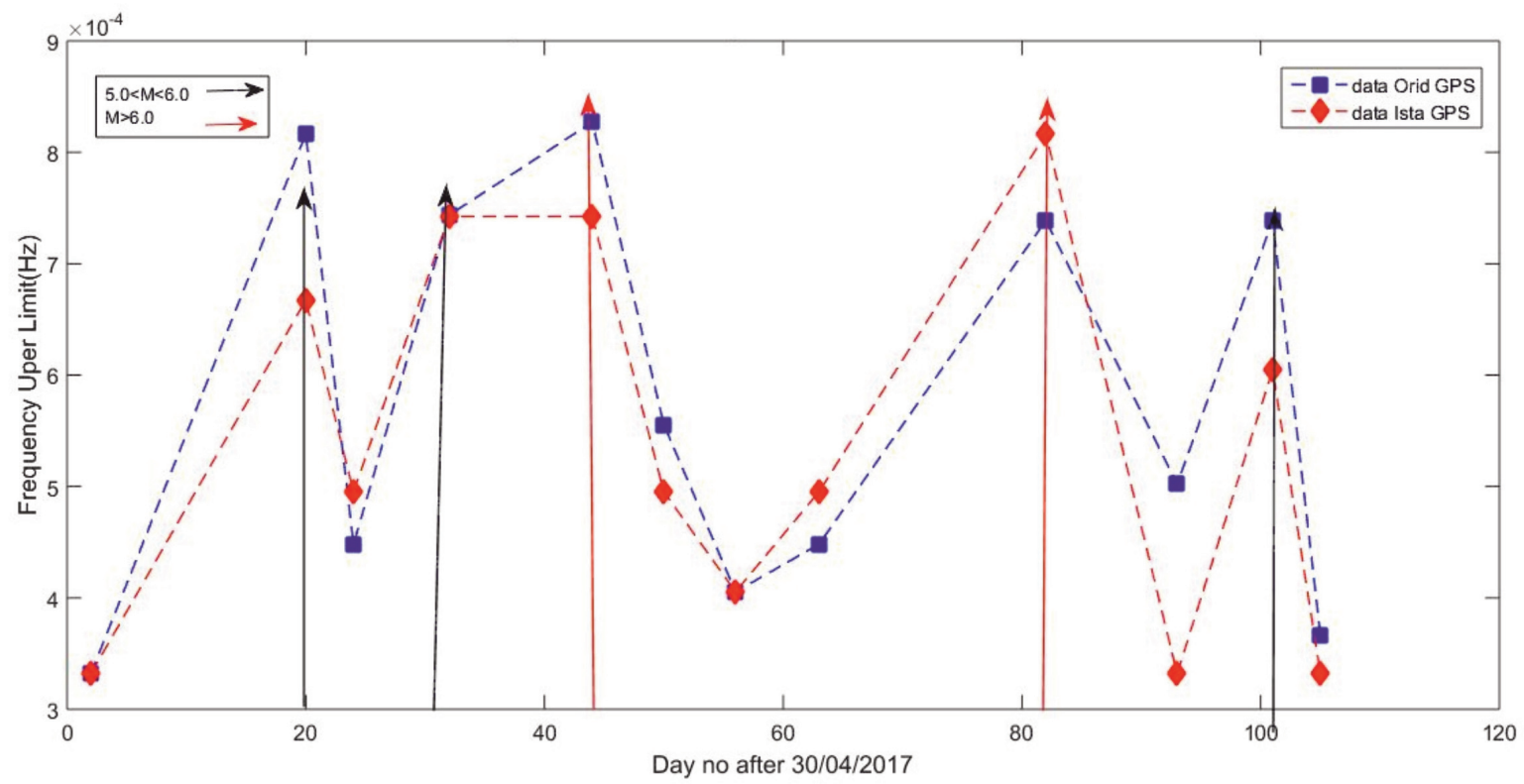

Figure 8. Time variation of TEC turbulence frequency limit $\mathrm{f}_{\mathrm{o}}$ over the closest to the active area GPS Stations of ORID and ISTA. It is seen that at the days that the strong earthquakes occurred, the frequency limit took its maximum values (red arrows).

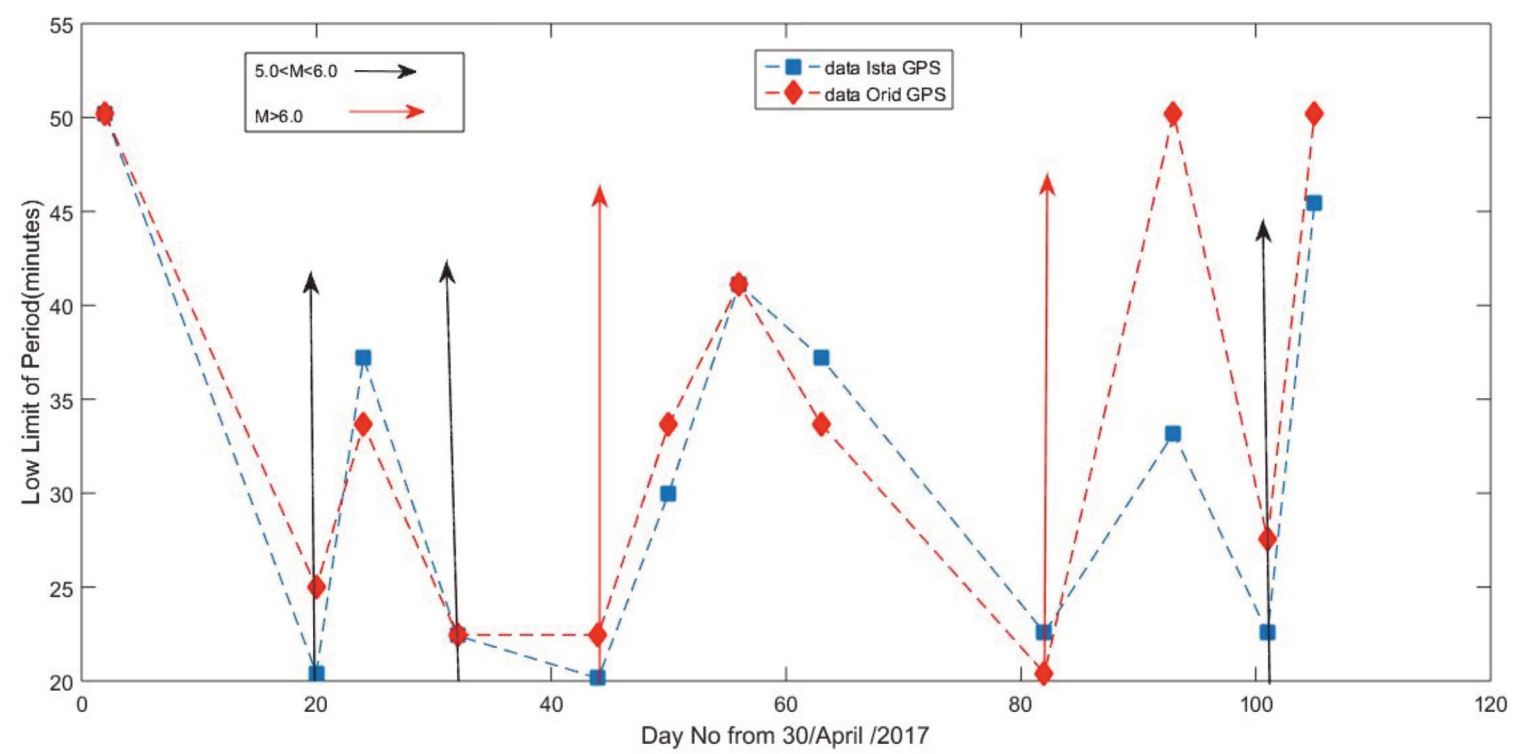

Figure 9. Time variation of TEC turbulence Period limit $\mathrm{P}_{0}$ over the closest to the active area GPS Stations of ORID and ISTA. It is seen that at the days that the strong earthquakes occurred, the period limit has minimum values (red arrows).

\section{Conclusion}

The results of our investigation, on the case of the recent East Aegean tectonic activity, indicate that the HighFrequency limit $\mathrm{f}_{\mathrm{o}}$, of the ionospheric turbulence content, increases as we approach the site and the time of the 
earthquake, pointing to the earthquake location. We conclude that the LAIC mechanism through acoustic or gravity wave could explain this phenomenology. That is, tectonic activity during the earthquake preparation period produces anomalies at the ground level, which propagate upwards in the troposphere as Acoustic or Standing gravity waves. These Acoustic or Gravity waves affect the turbulence of the lower ionosphere, where sporadic Es-layers may appear too, as well as the turbulence of the F layer. Subsequently the produced disturbance starts to propagate in the ionosphere's wave guide. Thus observing the frequency content of the ionospheric turbulence we will observe a decrease of the higher limit of the turbulence frequency band, as a result of the differential frequency attenuation of the propagating wave. Proper use of this observation may lead to a method of earthquake risk mitigation using the byproducts of the Global Positioning Network (actually TEC estimations) which are available freely.

\section{Reference}

Afraimovich, E. L., E. A. Kosogorov, K. S. Palamarchouk, N. P., Perevalova, and A, V. Plotnikov (2000). The use of GPS arrays in detecting the ionospheric response during rocket launching, Earth Planets Space, 52, 1061-1066.

Afraimovich, E. L., N. P. Perevalova, A. V. Plotnikov, and A. A. Uralov (2001). The shock acoustic waves generated by the earthquakes, Ann. Geophys., 19, 395-409, http://www.ann-geophys.net/19/395/2001/

Arikan, F., A. Yilmaz, O. Arikan, I. Sa Yin, M. Gurun, and S.A. Yildirim (2009). Space Weather Activities of IONOLAB Group: TEC Mapi, Geoph. Res. Abstr.,Vol 11.

Biagi, P. F., R. Piccolo, V. Capozzi, A. Ermini, S. Martellucci, and C. Bellecci (2003). Exalting in atmospheric tides as earthquakeprecursor, Nat. Hazards Earth Syst. Sci., 3, 197-201.

Contadakis, M. E., D. N. Arabelos, G. Asteriadis, S. D. Spatalas, and C. Pikridas (2008). TEC variations over the Mediterranean during the seismic activity period of the last quarter of 2005 in the area of Greece, Nat. Hazards and Earth Syst. Sci., 8, 1267-1276.

Contadakis, M. E., D. N. Arabelos, G. Asteriadis, S. D. Spatalas, and C. Pikridas (2012). TEC variations over Southern Europe before and during the M6.3 Abruzzo earthquake of $6^{\text {th }}$ April 2009, Ann. Geophys., 55, 1, 83-93.

Contadakis, M. E., D. N. Arabelos, G. Vergos, S. D. Spatalas, and E. M. Scordilis (2015). TEC variations over the Mediterranean before and during the strong earthquake $(M=6.5)$ of 12th October 2013 in Crete, Greece, Phys. Chem. Earth, 85, 9-16.

Dewey, J. F., and A. M. C. Sengör (1979). Aegean and surrounding regions: complex multiplate and continuum tectonics in a convergent zone, Geol. Soc. Am. Bull., 90, 84-92.

Freund, F.T. (2009). Stress-activated positive hole carriers in rocks and the generation of pre-earthquake signals, in: M. Hayakawa(ed.), Electromagnetic Phenomena Associated with Earthquakes, 41-96, Transworld Research Network,Trivandrum, India.

Hayakawa, M. (2011). On the fluctuation spectra of seismo-electromagnetic phenomena, Nat. Hazards Earth Syst. Sci., 11, 301-308.

Hayakawa, M., Y. Kasahara, T. Nakamura, Y. Hobara, A. Rozhnoi, M. Solovieva, O. A. Molchanov, and V. Korepanov (2011). Atmospheric gravity waves as a possible candidate for seismo-ionispheric perturbation, J. Atmos. Electr., 32, 3, 129-140.

Hayakawa, M., T. Asano, A. Rozhnoi, and M. Solovieva (2018). Very-low- and low-frequency sounding of ionospheric perturbations and possible association with earthquakes, in "Pre-earthquake Processes: A multidisciplinary approach to earthquake prediction studies”, Edited by D. Ouzounov et al., 277-304, AGU Book, Wiley.

Horie, T., S. Maekawa, T. Yamauchi and M. Hayakawa (2007). A possible effect of ionospheric perturbations associated with the Sumatra earthquake, as revealed from subionospheric very-low-frequency (VLF) propagation (NWC-Japan), Int. J. Remote Sensing, 28, 13, 3133-3139.

Hobara Y., F. Lefeuvre M. Parrot and O. A. Molchanov (2005). Low-latitude ionospheric turbulence observed by Aureol-3 satellite, Annales Geophysicae, 23, 1259-1270.

Ketin, I. (1948). Uber die tektonischmechanischen Folgerungen aus den grossen anatolischen Erdbeben des letzten Dezenniums, Geolog. Runds., 36, 77 - 83.

Kiratzi, A. (2018). The 12 June 2017 Mw 6.3 Lesvos Island (Aegean Sea) earthquake: Slip model and directivity estimated with finite-fault inversion, Tectonophysics, 724-725, https://doi.org/10.1016/j.tecto.2018.01.003.

LePichon X. and J. Angelier (1979).The Hellenic arc and trench system: a key to the neotectonic evolution of the 


\section{Emmanuel M. Scordilis et al.}

eastern Mediterranean area, Tectonophysics, 60, 1-42.

LePichon X. and J. Angelier (1981). The Aegean Sea, Philos. Trans. Royal Soc. London, A300, 357-372.

Liperovsky, V. A., C. V. Meister, E. V. Liperovskaya, N. E. Vasiliev and O. Alimov (2005). On spread-Es effects in the ionosphere before earthquakes, Nat. Hazards Earth Syst. Sci., 5, 59-62. http://www.nat-hazards-earth-systsci.net/5/59/2005/

Liu, J-Y, K. Hattor and Y-I Chen (2018). Application of Total Electron Content Derived from the Global Navigation Satellite System for Detecting Earthquake Precursors, in "Pre-earthquake Processes: A multidisciplinary approach to earthquake prediction studies”, Edited by D. Ouzounov et al., 305-318, AGU Book, Wiley

McKenzie D. P. (1972). Active tectonics of the Mediterranean region. Geophys, J. R. Astr. Soc., 30, 109-185.

McKenzie D. P. (1978). Active tectonics of the Alpine-Himalayan belt: the Aegean Sea and surrounding regions, Geophys. J. R. Astr. Soc., 55, 217-254.

Molchanov, O., P. F. Biagi, M. Hayakawa, A. Lutikov, S. Yunga, D. Iudin, S. Andreevsky, A. Rozhnoi, V. Surkov, V. Chebrov, E. Gordeev, A. Schekotov and E. Fedorov (2004). Lithosphere-atmosphere-ionosphere coupling as governing mechanism for preseismic short-term events in atmosphere and ionosphere, Nat. Hazards Earth Syst. Sci., 4, 5/6, 757-767.

Molchanov, O., A. Schekotov, M. Solovieva, E. Fedorov, V. Gladyshev, E. Gordeev, V. Chebrov, D. Saltykov, V. I. Sinitsin, K. Hattori and M. Hayakawa (2005). Near seismic effects in ULF fields and seismo-acoustic emission: statistics and explanation, Nat. Hazards Earth Syst. Sci., 5, 1-10.

Papazachos B.C. and P.E. Comninakis, (1970). Geophysical features of the Greek Island Arc and Eastern Mediterranean Ridge. “Com. Ren. Des Seances de la Conference Reunie a Madrid, 1969”, 16, 74-75.

Papazachos B. C. and P.E. Comninakis (1971). Geophysical and tectonic features of the Aegean arc. J. Geophys. Res., $76,8517-8533$.

Papazachos, B.C., E. E. Papadimitriou, A. A. Kiratzi, C. B. Papazachos and E. K. Louvari (1998). Fault plane solutions in the Aegean and the surrounding area and their tectonic implications, Boll. Geof. Teor. Appl., 39, 199-218.

Papazachos, B. C. and C. B. Papazachou (2003). The earthquakes of Greece, Ziti Publications, Thessaloniki, 273, (in Greek).

Pulinets, S., D. Ouzounov, A. Karelin and D. Davidenko (2018). Lithosphere-Atmosphere-Ionosphere-Magnetosphere Coupling-A Concept for Pre-Earthquake Signals Generation, in "Pre-earthquake Processes: A multidisciplinary approach to earthquake prediction studies", Ed. by D. Ouzounov et al., 79-99, AGU Book, Wiley

Saltogianni, V., T. Taymaz, S. Yolsal-Çevikbilen, T. Eken, M. Gianniou, T. Öcalan, S. Pytharouli and S. Stiros (2017). Fault-model of the 2017 Kos-Bodrum (east Aegean Sea) Mw 6.6 earthquake from inversion of seismological and GPS data, Preliminary Report, 4.

Sengör A., N. Gorur and F. Saroglu (1985). Strike-slip faulting and related basin formation in zones of tectonic escape: Turkey as a case study, In: Biddle, K. T. and Christe-Blick, N. (eds), "Strike-slip formation, basin formation and sedimentation, Soc. Economic Paleontologist and mineralogists”, Special Publication, 37, 227-265.

Svets, A. V., M. Hayakawa, O. A. Molchanov and Y. Ando (2004) A study of ionospheric response to regional seismic activity by VLF radio sounding, Phys. Chem. Earth, 29, 627-637.

Tiryakioğlu, I., B. Aktuğ, C.Ö. Yiğit, H. H. Yavaşoğlu, H. Sözbilir, Ç Özkaymak, F. Poyraz, E. Taneli, F. Bulut, A. Doğru and H. Özener (2018). Slip distribution and source parameters of the 20 July 2017 Bodrum-Kos earthquake (Mw6.6) from GPS observations, Geodinamica Acta”, 30:1, 1-14, doi:10.1080/09853111.2017.1408264.

Tramutoli, V., N. Genzano, M. Lisi and N. Pergola (2018) Significant Cases of Preseismic Thermal Infrared Anomalies, in "Pre-earthquake Processes: A multidisciplinary approach to earthquake prediction studies", Ed. by D. Ouzounov et al., 301-338, AGU Book, Wiley

Turcotte D. L. (1997). Fractal and Chaos in Geology and Geophysics (2 ${ }^{\text {nd }}$ Edition), Cambridge University Press, Cambridge U. K.

Watson, C., P. T. Jayachandran and J. W. MacDougall (2016). Characteristics of GPS TEC variations in the polar cap ionosphere. J. Geophys. Res. Space Physics, 121, 4748-4768, doi:10.1002/ 2015JA022275

Yalçıner, A., A. Annunziato, G. Papadopoulos, G., Güney-Doğan, H. Gökhan-Güler, T. Eray-Cakir, C. Özer-Sözdinler, E. Ulutaş, T. Arikawa, L. Süzen, U. Kanoğlu, I. Güler, P. Probst and C. Synolakis (2017). The 20th July 2017 (22:31 UTC) Bodrum-Kos Earthquake and Tsunami. Post Tsunami Field Survey Report, 116. 
Lower Ionospheric turbulence in Eastern Aegean

\section{WEB-sites}

http://users.metu.edu.tr/yalciner/july-21-2017-tsunami-report/Report-Field-Survey-of-July-20-2017-Bodrum-Kostsunami.pdf

GCMT, http://www.globalcmt.org/CMTsearch.html

*CORRESPONDING AUTHOR: Emmanuel M. SCORDILIS, Department of Geophysics, Aristotle University of Thessaloniki, Greece, e-mail:manolis@geo.auth.gr (c) 2020 the Istituto Nazionale di Geofisica e Vulcanologia. All rights reserved 